\title{
Comentário A "Outros Inconscientes: Desconstruindo a Translucidez da Consciência Sartriana”
}

\author{
Alberto Marcos Onate ${ }^{1}$
}

Referência do artigo comentado: ALT, F. Outros inconscientes: desconstruindo a translucidez da consciência sartriana. Trans/form/açáo: revista de filosofia da Unesp, v. 44, n. 4, p. 193-212, 2021.

Destaco, inicialmente, um aspecto positivo e dois aspectos negativos, no âmbito geral da abordagem adotada no artigo de Alt (2021): 1) A assunção, enquanto fio condutor da análise, tanto de maneira explícita quanto implícita, da noção de pré-reflexividade; 2.1) Dispersão de textos sartrianos mencionados e/ou citados, compreendendo de maneira uniforme escritos de momentos díspares do conjunto da obra filosófica do pensador francês; 2.2) Dispersão de intépretes e/ou filósofos mencionados e/ou citados, abrangendo um leque temático excessivo, em relação ao requerido pelo assunto proposto no artigo. $^{2}$ Trata-se de escolhas expositivas legítimas enquanto tais, mas que, no meu entender, comprometem a profundidade e a fecundidade filosóficas do que é efetivamente relevante e/ou irrelevante, na concepção sartriana de consciência/inconsciência, reflexividade/irreflexividade/pré-reflexividade.

1 Doutor em Filosofia pela Universidade de São Paulo (USP), pós-doutor (2007) em Filosofia pela Pontifícia Universidade Católica do Rio Grande do Sul (PUC-RS). Professor aposentado da Universidade Estadual do Oeste do Paraná (UNIOESTE-PR), Toledo, PR - Brasil. (D) https://orcid. org/0000-0002-9820-1315. E-mail: am.onate@uol.com.br.

2 Aspectos assinalados na avaliação do artigo e desconsiderados pela sua autora.

https://doi.org/10.1590/0101-3173.2021.v44n4.15.p213 
Em complemento à análise de sobrevoo (parafraseando Merleau-Ponty) desenvolvida no artigo, atenho-me à obra $A$ transcendência do ego eà conferência Consciência de si e conhecimento de si, bem como à valiosa introdução redigida pelo tradutor do livro e da conferência ao português de Portugal, visando a mostrar que a pré-refexividade não instaura "outros inconscientes", como sustenta a articulista, mas constitui um grave contrassenso da filosofia sartriana e da tradiçáo pensante em geral. ${ }^{3}$

Subintitulada Esboço de uma descrição fenomenógica, A transcendência do ego, ${ }_{4}^{4}$ pretende evidenciar que "[...] o ego não está na consciência nem formal nem materialmente: ele está fora, no mundo." (SARTRE, 1994b, p. 43). Encetando sua abordagem pelo eu penso kantiano, o pensador francês logo se dirige ao exame da noção husserliana de consciência transcendental, entendendo "[...] que o tipo de existência da consciência é o de ser consciência de si. E ela toma consciência de si enquanto ela é consciência de um objecto

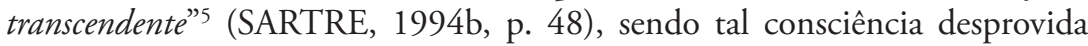
de qualquer egoidade, ao contrário do que defendia o pensador alemão. $\mathrm{O}$ principal equívoco husserliano (bem como, mutatis mutandis, cartesiano e kantiano) decorreria do privilégio atribuído a "[...] uma operação reflexiva, [...] uma operação de segundo grau" (SARTRE, 1994b, p. 50), na qual a consciência se tornaria objeto de si própria, mediante um ato tético da consciência refletinte (de segundo grau) em relação à consciência irrefletida (de primeiro grau). O resultado dessa dupla operação consciencial é a instauração do mim (moi), enquanto polo dos estados conscienciais, com seu sucedâneo $e u$ (je), enquanto polo dos atos conscienciais.

Sartre fornece exemplos dessa consciência irrefletida, a qual, a seu ver, foi obliterada pelo(a)s pensadore(a)s que o antecederam: 1) A absorção na leitura dum texto; 2) A corrida atrás dum veículo de transporte, cujo horário de chegada se descurou; 3) A contemplação dos detalhes dum retrato etc. No contexto do ataque às teorias defensoras duma presença material do mim em qualquer consciência, o filósofo francês formula teses que reputo decisivas, no tocante aos conceitos em discussão:

\footnotetext{
${ }^{3}$ Considerando os limites quantitativos estipulados pela revista para um comentário, serei o mais conciso possível.

${ }^{4}$ Redigida em 1934, durante a permanência de Sartre em Berlim, visando a aprofundar-se no pensamento de Husserl, e publicada inicialmente em francês, na revista Recherches philosophiques de 1936-1937.
}

${ }^{5}$ Mantenho o vocabulário português de Portugal, por fidelidade ao tradutor. 


\begin{abstract}
Mesmo se o inconsciente existe, a quem se poderia fazer crer que ele encerra espontaneidade de forma reflectida? A definição do reflectido não é o ser ele posto por uma consciência? Mas, além disso, como admitir que o reflectido é primeiro em relação ao irreflectido? Sem dúvida, pode conceber-se, em certos casos, que uma consciência apareça imediatamente como reflectida. Mas mesmo entáo o irreflectido tem prioridade ontológica sobre o reflectido, porque ele não tem de nenhum modo necessidade de ser reflectido para existir e porque a reflexão supóe a intervenção de uma onsciência de segundo grau. Chegamos, portanto, à seguinte conclusão: a consciênia irreflectida deve ser considerada autônoma. É uma totalidade que náo tem necessidade nenhuma de ser completada. (SARTRE, 1994b, p. 57).
\end{abstract}

$\mathrm{Na}$ conferência Consciência de si e conhecimento de si, ${ }^{6}$ o pensador francês reexamina e aprofunda esse âmbito conceitual-argumentativo. O cerne refere-se à possibilidade duma fiosofia fundada no cogito, seja na versão cartesiana, husserliana, numa conexáo ou mudança delas segundo parâmetros mais convincentes, ou, como último recurso, no abandono do cogito enquanto ponto de partida filosófico. O encaminhamento sartriano, desdobrado num fecundo campo conceitual e argumentativo, inviável de se recuperar nos limites deste comentário, parece-me bem condensado em certo momento da Apresentação da conferência: “4. Apenas o cogito pré-reflexivo fundamenta os direitos do cogito reflexivo e da reflexão. É a partir dele que se poderá formular o problema ontológico da apariçáo da consciência reflexiva e o problema lógico dos seus direitos a ser tida como apodíctica." (SARTRE, 1994c, p. 87).

Após a conferência, na sessão de perguntas, a última delas, e a mais relevante para nossa esfera temática, é posta por Hyppolite: "Será que a reflexão é, tal como o progresso, suscitada pela reflexão não-tética de si?” à qual o conferencista responde:

Não, trata-se de uma mistificação que vem desde a origem, mas no sentido de que a consciência irrefletida produz a consciência reflexiva como recuperação dela mesma. A consciência reflexiva é um esforço de saída e, ao mesmo tempo, de abarcamento da consciência por ela mesma. Ela não o consegue [...] (SARTRE, 1994c, p. 130).

Antes disso, o conferencista já respondera de maneira incisiva à indagação de Salzi, realçando a inutilidade da noção de inconsciente: "Trata-se de uma ilusão dos psicanalistas.” (SARTRE, 1994c, p. 124). De modo breve, esta é a posição sartriana resgatada sem dispersão.

\footnotetext{
${ }^{6}$ Proferida em 2 de junho de 1947, na Sociedade Francesa de Filosofia e cuja ata da sessão consta de Boletim da referida sociedade.
} 
Como arremate, sumario o essencial da apresentação crítica realizada pelo tradutor dos textos sartrianos, Pedro Alves, cujo título modesto Irreflectido e reflexão. Observaçóes sobre uma tese de Sartre, nos reserva uma análise de grande rigor e alcance. Um dos núcleos do exame crítico por ele desenvolvido concerne à hieraquia sartriana que subordina a reflexividade à irreflexividade ou pré-reflexividade, mediante indagaçóes radicais inspiradas no horizonte fenomenológico husserliano:

Pode o irreflectido ser entendido, à maneira de Sartre, como um nível absolutamente autónomo em relação à reflexão? Pode sequer a reflexão ser apresentada como um segundo acto que se vem simplesmente acrescentar à vivência irreflectida? Que é que exprime a verdadeira natureza da consciência: o facto de ela ser consciência imediata de objectos ou o princípio teleológico de ela tender para uma plena consciência de si? (ALVES, 1994a, p. 20-21).

Entendendo-se a fundo a noção husserliana de intencionalidade, como o faz Alves, ao dizer "[...] nada há na consciência que não seja consciência, ela está toda contida na sua relação ao objecto intencional, tudo nela é acto, não havendo aí nada semi ou inconsciente [...]" (ALVES, 1994a, p. 18), não se aquiesceria mais de maneira incauta a outros inconscientes, quer formulados por Sartre, quer por quaisquer outro(a)s pensadore(a)s.

\section{REFERÊNCIAS}

ALT, F. Outros inconscientes: desconstruindo a translucidez da consciência sartriana. Trans/form/açáo: revista de filosofia da Unesp, v. 44, n. 4, p. 193-212, 2021.

ALVES, P. M. S. Irreflectido e reflexão. Observaçóes sobre uma tese de Sartre. In: SARTRE, J-P. A transcendência do ego seguida de Consciência de si e conhecimento de si. Tradução e introdução de Pedro M. S. Alves. Lisboa: Colibri, 1994a.

SARTRE, J-P. A transcendência do ego. In: SARTRE, J-P. A transcendência do ego seguida de Consciência de si e conhecimento de si. Tradução e introdução de Pedro M. S. Alves. Lisboa: Colibri, 1994 b.

SARTRE, J-P. Consciência de si e conhecimento de si. In: SARTRE, J-P. A transcendência do ego seguida de Consciência de si e conhecimento de si. Tradução e introdução de Pedro M. S. Alves. Lisboa: Colibri, 1994c.

Recebido: $25 / 3 / 2021$

Aceito: 03/4/2021 